Article

\title{
Median to Strong Rainfall Intensity Favors Carbon Sink in a Temperate Grassland Ecosystem in China
}

\author{
Guangcun Hao ${ }^{1}$, Zhongmin $\mathrm{Hu}^{1,2, *}$, Qun Guo ${ }^{3,4}$, Kai $\mathrm{Di}^{1}$ and Shenggong $\mathrm{Li}^{3,4}$ \\ 1 School of Geography, South China Normal University, Guangzhou 510631, China; \\ haoguangc@m.scnu.edu.cn \\ 2 Southern Marine Science and Engineering Guangdong Laboratory, Zhuhai 519082, China \\ 3 Synthesis Research Center of Chinese Ecosystem Research Network, Key Laboratory of Ecosystem \\ Network Observation and Modeling, Institute of Geographic Sciences and Natural Resources Research, \\ Chinese Academy of Sciences, Beijing 100101, China \\ 4 College of Resources and Environment, University of Chinese Academy of Sciences, Beijing 100190, China \\ * Correspondence: huzm@m.scnu.edu.cn
}

Received: 31 August 2019; Accepted: 7 November 2019; Published: 13 November 2019

check for updates

\begin{abstract}
Over the past 50 years, rainfall events have made significant alterations to environments due to global warming. The grasslands in arid and semi-arid regions are extremely sensitive to variations in rainfall patterns, which are considered to significantly affect ecosystem functions. In this study, an experiment with varying rainfall sizes and frequencies $(0 \mathrm{~mm}, 2 \mathrm{~mm}, 5 \mathrm{~mm}, 10 \mathrm{~mm}, 20 \mathrm{~mm}$, and $40 \mathrm{~mm}$ ) was conducted during growing seasons in typical grasslands, to study the effect of changes in rainfall regime on net ecosystem exchange (NEE). Our results indicated that NEE exhibited nonlinear responses to rainfall treatments, and reached its peak under $20 \mathrm{~mm}$ in middle growing season. Further, the component fluxes of both NEE (i.e., gross primary productivity (GPP)) and ecosystem respiration (ER) illustrated nonlinear responses to treatment gradient, with peak values at $20 \mathrm{~mm}$ and $5 \mathrm{~mm}$, respectively. Based on five-year eddy flux measurements, further analyses demonstrated that GPP and ER increased with increasing soil moisture, and net ecosystem carbon uptake $\left(-1^{*} \mathrm{NEE}\right)$ was significantly stimulated due to a more enhanced GPP than ER, when soil moisture was above $8 \%$. Additionally, we found that the response of root biomass was different from that of carbon fluxes to changes in rainfall patterns. Overall, these findings highlight the importance of both changes in rainfall regimes in controlling ecosystem $C$ exchange and investigation of the potential threshold for ecosystem function shifts, which are crucial to further understand C cycles in grasslands.
\end{abstract}

Keywords: climate change; rainfall pattern; grassland; ecosystem carbon exchange

\section{Introduction}

Rainfall inputs alter ecosystem processes (e.g., primary production) and community structures over short (hourly and daily) and long (seasonal and yearly) timescales [1,2]. Over the past decades, there has been an amplification of the hydrological cycle due to global warming [3]. Changes in amount, frequency, intensity, and extremes of regional rainfall by alteration of the hydrological cycle have been broadly observed [3-5]. Rainfall appears to shift from more frequent and smaller to fewer and larger precipitation events without change in total rainfall amount [6,7]. Therefore, it is essential to understand the response of ecosystem processes to changes in rainfall regime, especially for water-limited ecosystems.

Grassland ecosystems in arid and semiarid regions cover about $20 \%$ of land surface area and store about $10 \%$ of global soil organic carbon [8]. They dominate the trend and inter-annual variability of carbon sink, thus playing a critical role in carbon-climate feedback [9]. In grasslands, $\mathrm{CO}_{2}$ exchange 
is also controlled by variations in water availability [10-12]. Therefore, there is a strong relationship between carbon cycle and rainfall inputs $[13,14]$. However, the response of $\mathrm{CO}_{2}$ exchange to changes in rainfall regimes is unknown.

Net ecosystem exchange (NEE), the balance between gross primary productivity (GPP) and ecosystem respiration (ER), is the shift signal from carbon source to sink, closely linking with the intensity of rainfall in grasslands [10,15-17]. The different sensitivities of GPP and ER to variation in the intensity and frequency of rainfall control the magnitude and direction of NEE [1]. The sensitivity of GPP and ER varies along with change in rainfall patterns; therefore, it is difficult to predict the response of NEE to variations in rainfall. For example, small rainfall events may result in a larger degree of increase of ER than GPP; NEE is then found to be positive (carbon source) [18]. However, large rainfall events may result in a greater degree of augmentation of GPP than ER; NEE is then found to be negative (carbon sink) [10]. Therefore, there exists a rainfall threshold to meet the tipping point of NEE, along with changes in rainfall patterns when NEE moves from positive (source) to negative (sink). Unfortunately, the rainfall threshold has not yet been confirmed. Considering that changes in rainfall patterns in climate change experiments are key processes for understanding and predicting potential trends in $\mathrm{CO}_{2}$ fluxes in semi-arid and arid regions in response to advancing climatic changes, it is an urgent need to seek for a rainfall threshold to explore the response of NEE to the variation in rainfall patterns.

In grassland ecosystems, plant roots significantly impact ecosystem $\mathrm{CO}_{2}$ fluxes to cope with the limit of water availability [19]. Rooting depth is sensitive to precipitation infiltration depth [20]. Large rainfall events infiltrate much deeper than smaller ones [1,21]; therefore, rooting depth may be caused by large rainfall events. With variation in rainfall regimes in the future, rooting dynamics will be closely connection with rainfall events. However, we have little information on how root dynamics responds to changes in rainfall frequency and size of grasslands. In addition, GPP and ER have a significantly positively relationship with root production [22]. For example, an enhanced GPP will increase root production, and ER depends on root productivity [19]. Also, it is unknown whether the response of carbon fluxes has as consistent a trend as the response of root production to change in rainfall patterns.

In order to examine the key gaps, we conducted three-year experiments in rainfall regimes with a gradient of five rainfall addition levels $(0 \mathrm{~mm}, 2 \mathrm{~mm}, 5 \mathrm{~mm}, 10 \mathrm{~mm}, 20 \mathrm{~mm}$, and $40 \mathrm{~mm})$ during growing seasons in semi-arid grasslands in Inner Mongolia, China. The rainfall addition gradient offers the possibility to test how NEE responds to change in rainfall regimes. We also measured carbon fluxes (NEE, ER, and GPP) and primary production (aboveground biomass and belowground biomass), and quantified the relationship between soil moisture and the above-mentioned carbon processes at an ecosystem scale. The purposes of this study are to (i) reveal the general response patterns of NEE to changes in rainfall patterns; (ii) examine the response patterns of root productivity to changes in rainfall patterns; and (iii) compare the response of carbon fluxes and root production to changes in rainfall patterns.

\section{Materials and Methods}

\subsection{Site Description}

The rainfall experiment was conducted in semi-arid grasslands at the Duolun Restoration Ecology Station at the Institute of Botany $\left(42^{\circ} 02^{\prime} \mathrm{N}, 116^{\circ} 117^{\prime} \mathrm{E}\right)$, which is located in Inner Mongolia province, China. Its long-term mean annual precipitation was $382.2 \mathrm{~mm}$ from 1953 to 2006, with about $80 \%$ of annual precipitation falling in the growing season (May to October). Its long-term mean annual temperature was $2.1{ }^{\circ} \mathrm{C}$ from 1952 to 2008 , with an average low of $-17.5^{\circ} \mathrm{C}$ in January and a high of $18.9^{\circ} \mathrm{C}$ in July $[5,6]$. Its soil type is classified as Haplic Calcisols, according to Food and Agriculture Organization (FAO) classification. The concentration of the soil's organic $C$, nitrogen, and phosphorus is $0.16 \%, 0.17 \%$, and $0.28 \%$, respectively [23]. The vegetation is this region is a typical steppe community, which includes Artemisia frigida Willd, Stipa krylovii Roshev., and Agropyron cristatum (L.) Gaertn [24]. 


\subsection{Experimental Design}

During the growing seasons of 2015, 2016, and 2017, we manipulated a random block design experiment with four replicates to simulate the changes in precipitation pattern. The experiment consisted of $25.4 \times 3 \mathrm{~m}$ plots that were established in 2012, and 20 of them were randomly assigned to one of five rainfall variability treatments. Ambient rain plots without treatments were used as controls by only receiving natural rainfall. During the growing seasons, each treatment plot was irrigated using a sprinkling can of local groundwater. The water used for irrigation was obtained from a reverse-osmosis system. We added the same amount of precipitation $(80 \mathrm{~mm}$, ca. $20 \%$ of MAP) over the growing season, but varied the size and frequency of applied precipitation events (Table 1).

Table 1. The number, frequency, and start date of the rainfall treatment.

\begin{tabular}{cccccc}
\hline Rainfall Treatment & $\mathbf{2} \mathbf{~ m m}$ & $\mathbf{5} \mathbf{~ m m}$ & $\mathbf{1 0 ~} \mathbf{~ m}$ & $\mathbf{2 0 ~} \mathbf{~ m}$ & $\mathbf{4 0} \mathbf{~ m m}$ \\
\hline Number & 40 & 12 & 6 & 3 & 2 \\
Frequency & 2 days & 3 days & 7 days & 15 days & 1 month \\
Start date & June 1 & June 1 & June 1 & June 1 & Mid-July \\
\hline
\end{tabular}

\subsection{Measurement of $\mathrm{CO}_{2}$, and Abiotic and Biotic Variables}

Ecosystem $\mathrm{CO}_{2}$ fluxes, ecosystem respiration (ER), and net ecosystem exchange (NEE) were directly measured in middle growing season (July to August) by a multichannel automated measurement system developed by the National Institute for Environmental Studies of Japan. The system consists of an infrared gas analyzer (IRGA, Li-840, Li-Cor Inc., Lincoln, USA) and a data logger (CR3000, Campbell Scientific, Inc., Logan, UT, US). More details on this multichannel automated measurement system can be found in our previous studies [5,6]. In each plot, the system measured NEE (with sunlight) and ER (with lightproof cloth covering). Each measurement lasted $150 \mathrm{~s}$. The data logger monitored the $\mathrm{CO}_{2}$ concentration output signals from the IRGA at a rate of $1 \mathrm{~Hz}$ and recorded their averages at 10-s intervals. Only mid-values of $130 \mathrm{~s}$ (deleting the first and last $10 \mathrm{~s}$ ) were used [5,6] to calculate the flux, as shown in Equation (1):

$$
F=\left((V \times P(1-W) /(R \times S \times T)) \times\left(U_{c} / U_{t}\right)\right.
$$

where $F$ is the $\mathrm{CO}_{2}$ flux (umol m${ }^{-2} \mathrm{~s}^{-1}$ ) (NEE or ER), $V$ is the volume of the chamber $\left(\mathrm{m}^{3}\right), P$ is the air pressure (Pa), $W$ is the water vapor mole fraction, $R$ is the universal gas constant $\left(8.314 \mathrm{~J} \mathrm{~mol}^{-1} \mathrm{~K}^{-1}\right)$, $S$ is the base area of the chamber $\left(\mathrm{m}^{2}\right), T$ is the air temperature in the chamber $(\mathrm{K})$, and $U_{c} / U_{t}$ is the rate of increase in the $\mathrm{CO}_{2}$ mole fraction $\left(\mathrm{mmol} \mathrm{mol}^{-1} \mathrm{~s}^{-1}\right)$ in the chamber calculated by least squares. Negative NEE indicates that the ecosystem absorbs $\mathrm{CO}_{2}$ from the atmosphere, while positive values indicate $\mathrm{CO}_{2}$ emission.

We used Equation (2) to assess daytime ecosystem respiration $\left(E R_{d}\right)$ due to nighttime fluxes representing night ecosystem respiration:

$$
E R_{d}=E R_{r e f} \times\left(b_{1}+b_{2} S W C\right) \times\left(\frac{T_{s}-T_{r e f}}{10}\right)
$$

where the $E R_{r e f}$ is the ecosystem respiration at the reference temperature $\left(10^{\circ} \mathrm{C}\right)$ and optimal soil moisture, $T_{s}$ is the soil temperature, $b_{1}$ and $b_{2}$ are constant coefficients evaluated from the linear relationship between nighttime ER, temperature, and SWC. Finally, GPP was indirectly estimated as Equation (3):

$$
\mathrm{GPP}=E R_{d}-N E E
$$

There were two thermocouples in each chamber to measure air temperature and soil temperature (at a depth of $5 \mathrm{~cm}$ ) at the same time as $\mathrm{CO}_{2}$ flux. Soil water content at depths of $10 \mathrm{~cm}, 20 \mathrm{~cm}, 30 \mathrm{~cm}$, and $40 \mathrm{~cm}$ were measured every three days by Diviner 2000 (Sentek Pty. Ltd., Australia). 
Aboveground biomass (AGB) and belowground biomass (BGB) were clipped in a $1 \times 1 \mathrm{~m}$ quadrat of each plot on 15 August. All living plants (AGB) above the soil surface were clipped by the harvest method [17]. For each year, the locations of quadrats were randomly changed to prevent resampling of the same quadrat. Plant root (BGB) were estimated at three depths $(0-10 \mathrm{~cm}, 10-20 \mathrm{~cm}$, and 20-40 cm) with an iron tube (10 $\mathrm{cm}$ diameter and $1 \mathrm{~m}$ length), based on soil coring methods.

\subsection{Eddy Flux Measurement (EC)}

In order to further detect the relationship between soil moisture and carbon flux, half-hourly fluxes of $\mathrm{CO}_{2}$, water vapor, and sensible heat above the canopy were measured continuously using the EC technique near the field experiment (far from $100 \mathrm{~m}$ ) from 2012 to 2016. In addition, air temperature, rainfall, and soil moisture at three depths $(0-5 \mathrm{~cm}, 5-20 \mathrm{~cm}$, and $20-40 \mathrm{~cm})$ were also recorded at each 30-min interval. Quality control and gap-filling were performed by following the standard China Flux processing method [25]. ER and GPP were calculated based on Equations (2) and (3). In order to eliminate the effects of yearly variation in leaf area, NEE, ER, and GPP were normalized with a division of leaf area index (LAI). Leaf area index LAI was calculated by models developed by Hu et al. [25] ( $\left.\mathrm{LAI}=0.106 \mathrm{e}^{4.064 \mathrm{NDVI}}, \mathrm{R}^{2}=0.94\right)$. NDVI data were obtained by using the Moderate Resolution Imaging Spectroradiometer with 8-d time resolution and 250-m spatial resolution (http://daac.ornl.gov/MODI/modis.html).

\subsection{Statistical Analysis}

We analyzed the experimental data based on linear mixed-effects models. First, we tested the effects of rainfall treatments on ecosystem production and C fluxes, as well as abiotic factors (soil moisture, soil temperature, soil $\mathrm{C}$ and $\mathrm{N}$ content). Then we conducted ANOVA to examine inter-annual variability in response variables, when combined with rainfall treatments. Because response variables significantly differ between years, we also tested the impact of rainfall treatments on carbon fluxes (NEE, ER and GPP) during middle growing season in each year. In linear mixed-effects models, rainfall treatments and time (i.e., year) were included as fixed factors, and block was included as a random effect. The Least Significant Difference (LSD) test was used to compare the differences for AGB, BGB, and soil moisture at different depths among treatments. Nonlinear regression analysis was used to correlate BGB to soil moisture at a depth of $20-40 \mathrm{~cm}$.

In order to determine the relative importance of soil temperature and soil moisture on NEE, ER, and GPP in the early and middle growing seasons, we analyzed the relationship between soil moisture, soil temperature, and carbon fluxes (NEE, ER, and GPP) based on eddy flux measurement using a linear mixed effect model. In the model, soil moisture and temperature were included as fixed factors, and the experimental years were treated as a random factor. The proportion of variance $\left(\mathrm{r}^{2}\right)$ explained by different factors was also calculated using the linear mixed effect model. Linear regression was used to correlate carbon fluxes (NEE, ER, and GPP) (normalized by LAI) to soil moisture in different growing periods.

\section{Results}

\subsection{Influence of Rainfall Additions on Abiotic Factors}

The three experiment years (2015-2017) were humid years with natural rainfall of 280, 330 and $283 \mathrm{~mm}$, respectively, in the growing season (Figure S1). Soil moisture was increased under added rainfall, compared to ambient $(p<0.05)$, and was significant higher in $20 \mathrm{~mm}$ treatments than the other treatments at a depth of $10-20 \mathrm{~cm}$ in middle growing season (Figure 1) 

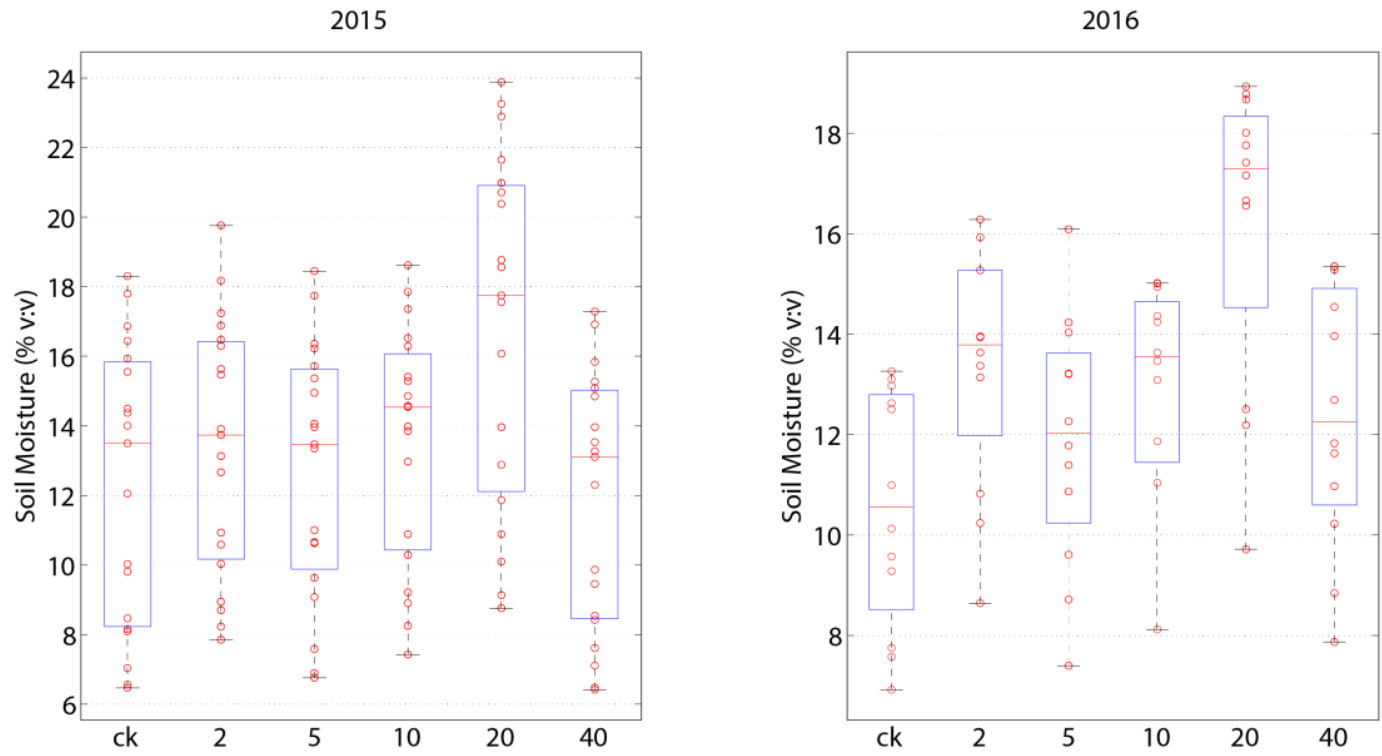

Figure 1. Soil moisture under different treatments at a depth of $10-20 \mathrm{~cm}$ in the middle growing season. ck: ambient control, $2 \mathrm{~mm}$ : $2 \mathrm{~mm}$ treatment; $5 \mathrm{~mm}$ : $5 \mathrm{~mm}$ treatment; $10 \mathrm{~mm}$ : $10 \mathrm{~mm}$ treatment; $20 \mathrm{~mm}$ : $20 \mathrm{~mm}$ treatment; $40 \mathrm{~mm}$ : $40 \mathrm{~mm}$ treatment. The different letters represent significantly different rainfall treatments $(p<0.05)$.

\subsection{Influences of Rainfall Additions on Plant Biomass}

Rainfall treatments had no significant impact on AGB, BGB, and soil C:N (Table S1). Their AGBs were consistently higher than those from ambient precipitation (Figure S2). However, BGB was the highest under $2 \mathrm{~mm}$ treatment at a depth of $0-10 \mathrm{~cm}$ (Figure 2). At a depth of $20-40 \mathrm{~cm}$, the response of BGB to rainfall treatment followed a consistent trend in 2015 and 2016, and the highest and lowest biomasses were under $10 \mathrm{~mm}$ and $5 \mathrm{~mm}$ treatment, respectively (Figure 2). Moreover, we found a significant quadratic relationship between BGB and soil moisture at a depth of 20-40 cm (Figure 3).
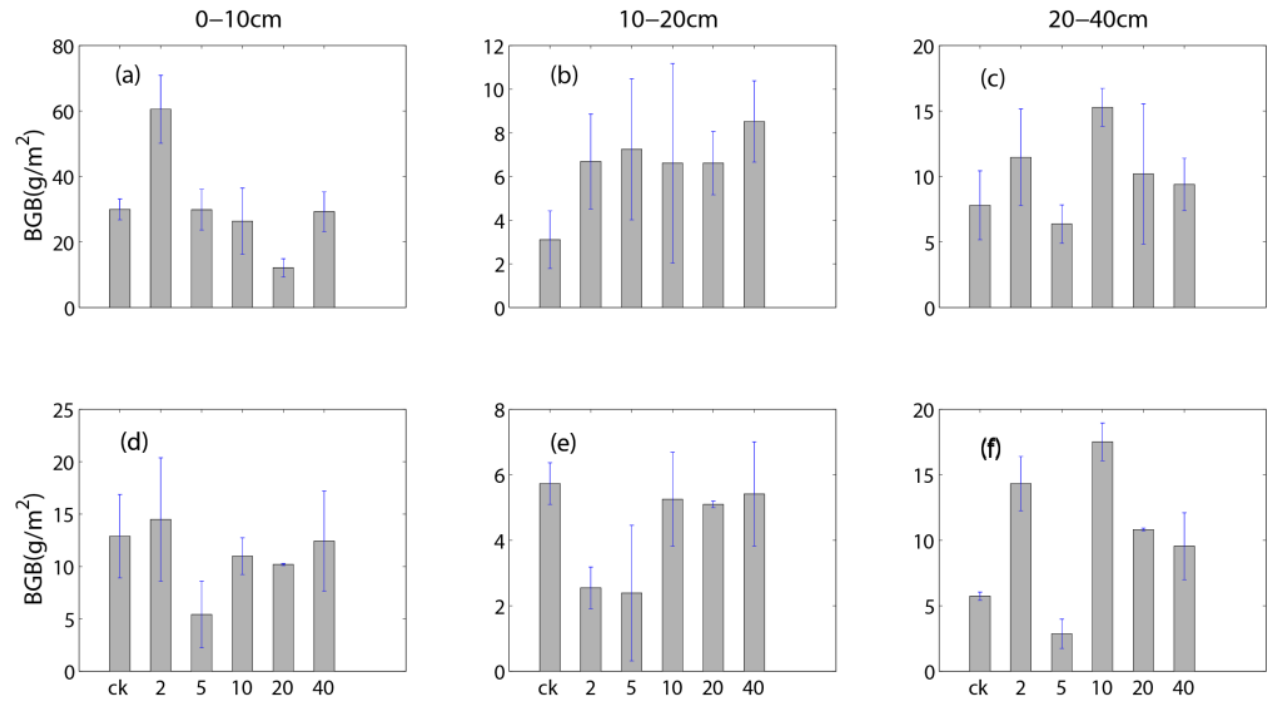

Figure 2. Response of belowground biomass (BGB) to rainfall treatments at different depths in 2015 $(\mathbf{a}-\mathbf{c})$ and 2016 (d-f). ck: ambient control, $2 \mathrm{~mm}: 2 \mathrm{~mm}$ treatment; $5 \mathrm{~mm}$ : $5 \mathrm{~mm}$ treatment; $10 \mathrm{~mm}$ : $10 \mathrm{~mm}$ treatment; $20 \mathrm{~mm}$ : $20 \mathrm{~mm}$ treatment; $40 \mathrm{~mm}$ : $40 \mathrm{~mm}$ treatment. Error bars show standard errors. 0-10 cm, 10-20 cm, and 20-40 cm represents soil depth. 

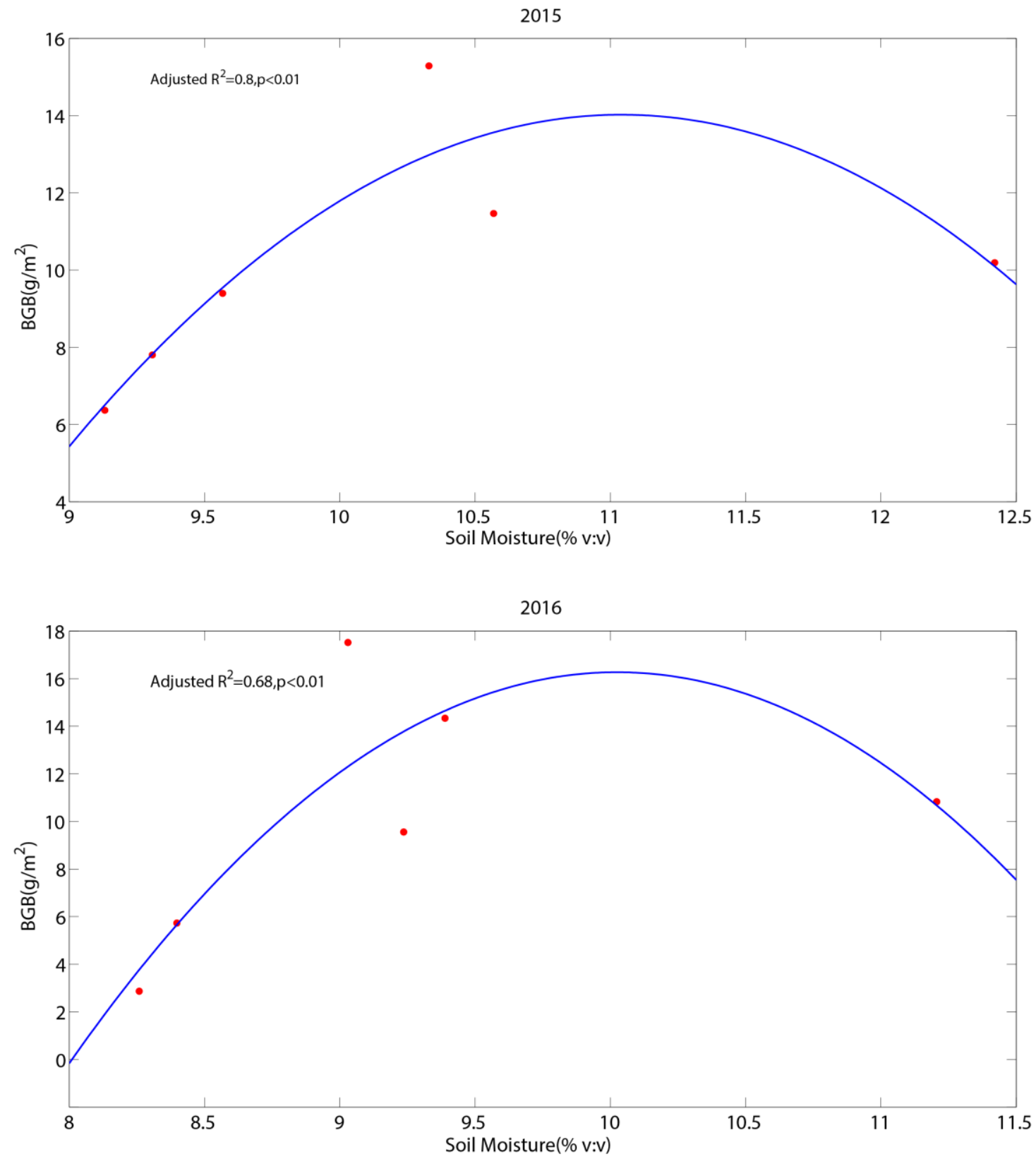

Figure 3. Relationship between belowground biomass (BGB) and soil moisture at a depth of $20-40 \mathrm{~cm}$ in 2015 (top) and 2016 (bottom) based on nonlinear regression analysis.

\subsection{Influences of Rainfall Additions on C Balance}

In middle growing seasons, rainfall treatment significantly affected NEE at the annual scale (Figure S3, $p<0.05)$. Overall, net ecosystem $\mathrm{CO}_{2}$ uptake $\left(-1^{*} \mathrm{NEE}\right)$ was stimulated in comparison with ambient treatment over three experimental years (Figure 4). Net ecosystem $\mathrm{CO}_{2}$ uptake initially increased and subsequently leveled off after $20 \mathrm{~mm}$ rainfall treatment (Figure 4), which was consistent with that of soil moisture (Figure 1). Also, we found significant effect of rainfall treatments on GPP and ER across three experimental years (Figure S3, $p<0.05$ ). Rainfall treatments stimulated ER first, and then suppressed ER after the 5-mm treatment. Additionally, GPP, with the same trend as NEE, was stimulated under $20 \mathrm{~mm}$ treatment, and suppressed under the $40-\mathrm{mm}$ treatment (Figure 4). 

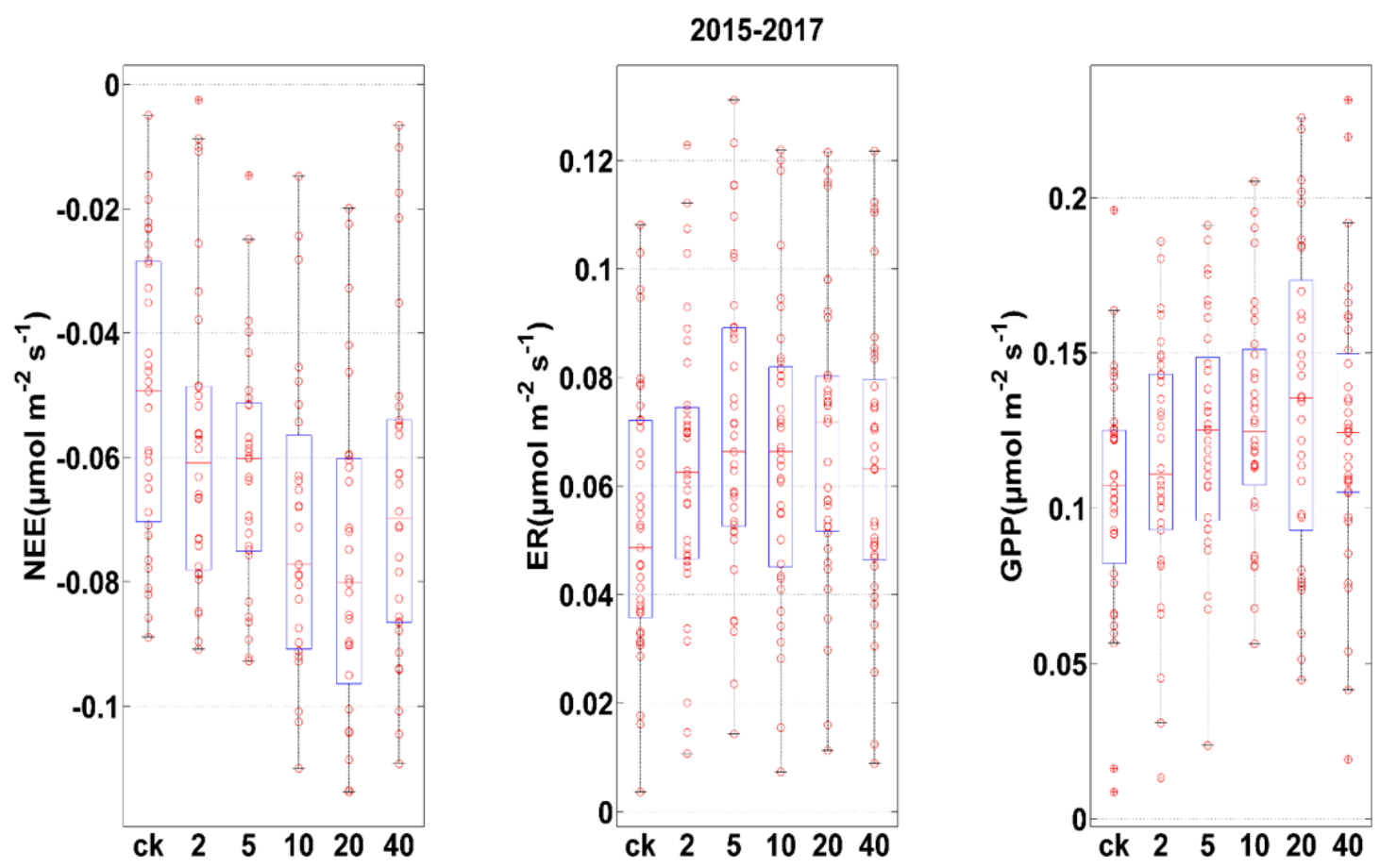

Figure 4. Responses of NEE (net ecosystem exchange), ER (ecosystem respiration), and GPP (gross primary production) to different rainfall treatments over three experiment years in middle growing season. ck: control, 2: $2 \mathrm{~mm}$ treatment, 5: $5 \mathrm{~mm}$ treatment, 10: $10 \mathrm{~mm}$ treatment, 20: $20 \mathrm{~mm}$ treatment, 40: $40 \mathrm{~mm}$ treatment. The black and grey lines within the box represent the median and mean of the carbon fluxes, respectively, across three sampling years (2015, 2016, and 2017); box limits indicate carbon fluxes in the 25th-75th percentile range. Error bars indicate the 10th and 90th percentiles. The open dots show the distribution of carbon fluxes data in each treatment.

\subsection{The Relationship Between Abiotic Factors and Carbon Fluxes}

Overall, soil moisture and temperature had significant effects on carbon fluxes (NEE, ER, and GPP) (Tables S2 and S3). In early growing seasons, soil temperature had more significant effects on NEE (explained around $7 \%-8 \%$ of the variation) than soil moisture $(0.5 \%-3 \%$ of the variation) (Figure $5 \mathrm{a}, \mathrm{c}$ ). In middle growing seasons, soil moisture had a more significant effect on NEE (explained $14 \%$ of the variation) than soil temperature $(0.6 \%)$ (Figure $5 b, d)$.

GPP and ER were both significantly impacted by soil moisture in early and middle growing season. In early growing seasons, soil moisture at the depth of $0-20 \mathrm{~cm}$ explained around $40 \%$ of the changes in GPP and ER (Figure $5 \mathrm{a}, \mathrm{c}$ ). In middle growing seasons, soil moisture explained about $20 \%$ more of the changes in GPP and ER than that in the early growing season (Figure 5b,d).

In early and middle growing seasons, GPP and ER were stimulated with the increasing soil moisture (Figures S4 and S5). Moreover, the response of GPP to soil moisture at a depth of 0-20 cm was more sensitive than that of ER, which was indicated by the greater slope of the regression function in middle growing seasons (Figure 6). Additionally, net ecosystem carbon uptake was stimulated when soil moisture was larger than $8 \%$ (v:v), because GPP was more largely stimulated than ER (Figure 6). 
$0-10 \mathrm{~cm}$

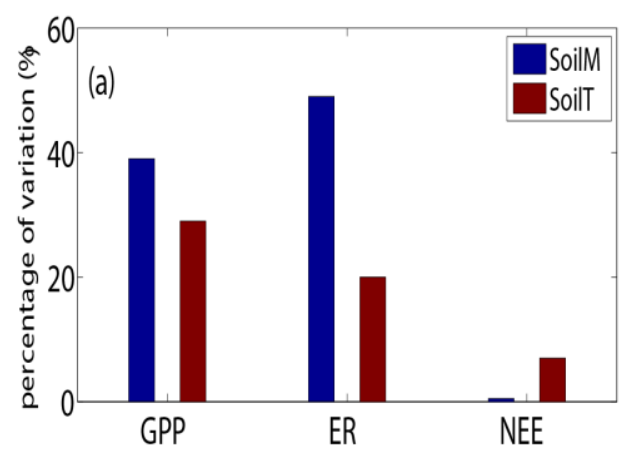

$10-20 \mathrm{~cm}$

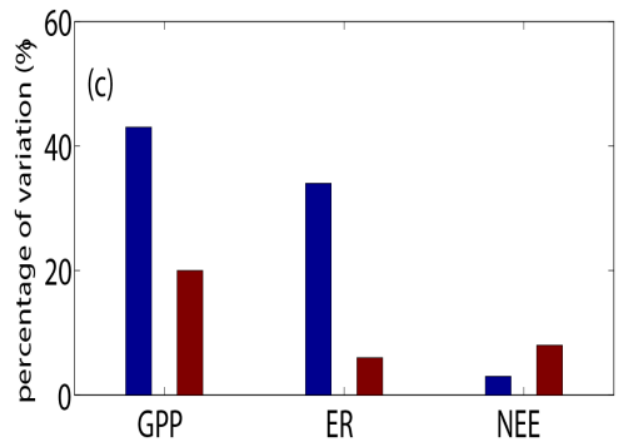

$0-10 \mathrm{~cm}$

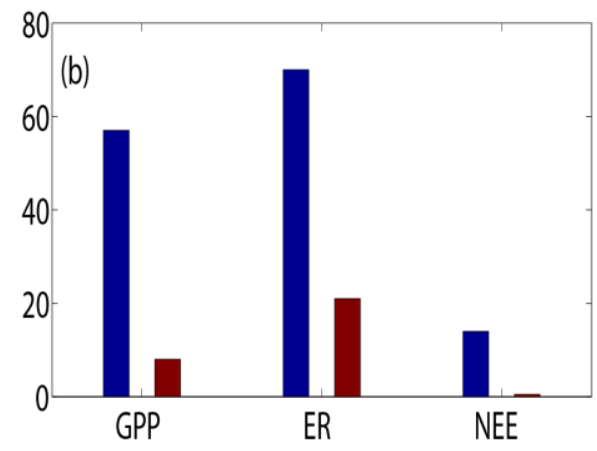

$10-20 \mathrm{~cm}$

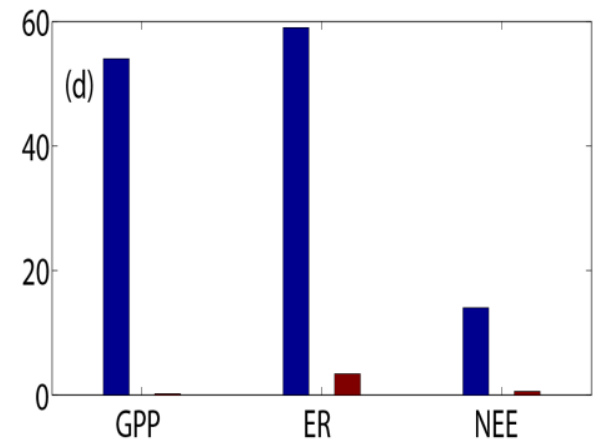

Figure 5. The percentage of variation in NEE (net ecosystem exchange), ER (ecosystem respiration), and GPP (gross primary production) explained by soil moisture (SoilM) and soil temperature (SoilT), as determined by linear mixed-effects models from 2012 to 2016 in the early growing season $(\mathbf{a}, \mathbf{c})$ and middle growing season $(\mathbf{b}, \mathbf{d})$.

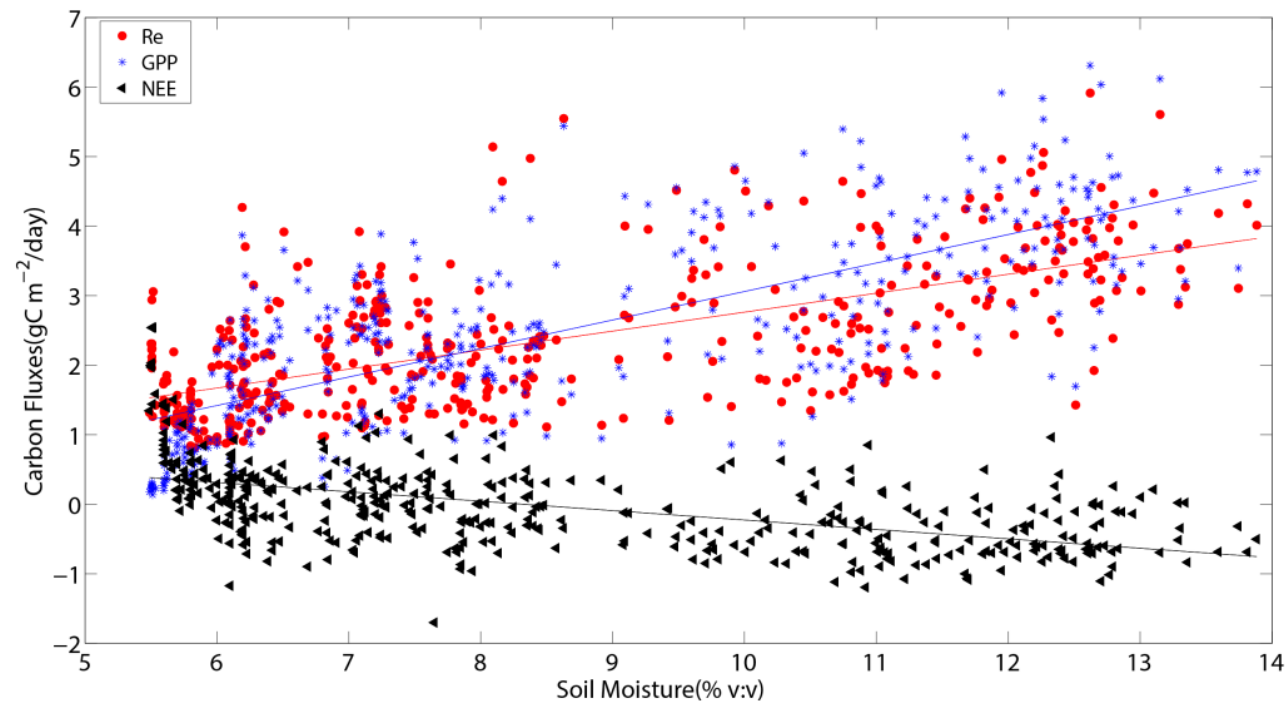

Figure 6. The relationship between average soil moisture at a depth of $0-20 \mathrm{~cm}$ and NEE (net ecosystem exchange), ER (ecosystem respiration), and GPP (gross primary production) in middle growing season.

\section{Discussions}

Our results showed that with rainfall treatments in a typical grassland, net ecosystem $\mathrm{CO}_{2}$ uptake $\left(-1^{*} \mathrm{NEE}\right), \mathrm{ER}$, and GPP first increased, and then decreased, with the peak at a threshold of $20 \mathrm{~mm}$, $5 \mathrm{~mm}$, and $20 \mathrm{~mm}$, respectively (Figure 4). Our results also indicate that BGB has strong linkages with soil moisture, induced by changes in rainfall patterns. 


\subsection{Effect of Change in Rainfall Patterns on Carbon Fluxes}

Net ecosystem $\mathrm{CO}_{2}$ uptake reached its peak with change in rainfall patterns. There appears to exist a critical rainfall threshold under the change in rainfall patterns, below which rainfall suppresses net $\mathrm{CO}_{2}$ uptake. If rainfall exceeds this threshold, net $\mathrm{CO}_{2}$ uptake decreases. The hump-shaped response pattern of GPP was similar to that of NEE. This is because GPP, especially in summer, controls the variation in NEE during the growing seasons $[26,27]$. Nevertheless, there were a few differences in the responses to ER and NEE, which can be attributed to two reasons: First, larger rainfall may decrease ER due to a reduction in $\mathrm{O}_{2}$ concentration with increasing soil moisture [28]. Second, previous studies have considered that changes in rainfall frequency may cause significant differences in soil substrate content of microbial respiration [29]. In our study, however, soil C:N ratio did not show significant differences under our treatments.

At the Duolun site, the percentage of natural rainfall events greater than $20 \mathrm{~mm}$ was $8.24 \%$ (the maximum $32.6 \mathrm{~mm}$ in total 182 rainfall events from 2012 to 2016); therefore, $40 \mathrm{~mm}$ can be considered as an extreme precipitation event (EPE). Our results show that EPE increases net $\mathrm{CO}_{2}$ uptake in middle growing seasons in comparison with natural rainfall treatments, which was consistent with the observation from natural rainfall [30]. However, the effect of EPE on NEE still lacks consistent agreement $[16,30]$ due to discrepant treatments in current EPE experiments. In current opinion, EPE significantly affects NEE at short timescale (e.g., during treatment) [16,17], but NEE is not effected by EPE on a long timescale (e.g., after treatment or multi-year recurrence) due to ecosystem resistance [31] or stress memory [32].

\subsection{Effects of Change in Precipitation Patterns on Biomass}

Our results also supported the view that AGB rose with increasing within-season rainfall variability [33]. However, rainfall treatments did not significantly alter AGB, which was attributed to several reasons. First, plant biomass is limited by multiple nutrients [34-36]. Soil N content may become the dominated factor when rainfall is abundant [36-38]. Second, species richness (up to 30 species in our field) improvs the resistance of plant communities, thus keeping communities stable when facing extreme rainfall (e.g., $40 \mathrm{~mm}$ treatments) [39].

Additionally, the distribution of BGB at surface depth $(0-10 \mathrm{~cm})$ may be closely related to more and less rainfall intensity, because the duration of soil moisture was longer during the treatments. At a deeper depth $(20-40 \mathrm{~cm})$, soil moisture content controlled the distribution of BGB. Moreover, BGB seemed to reach its peak when soil moisture is around $10 \%$, and root turnover rate may be stimulated above the threshold [19]. Although less than $30 \%$ of root is distributed at a depth of $20-40 \mathrm{~cm}$, deep root was significantly important in connecting the hydrologic cycle and climate during dry periods, thus regulating long-term carbon cycles [20].

\subsection{Different Responses of Carbon Fluxes and Root Biomass}

Previous studies have argued that the rising BGB with increasing rainfall is attributed to enhanced GPP $[17,19]$. However, no positive relationship between BGB and GPP was found in our study. This could be the reason why BGB is more sensitive to total rainfall amount [17,40]. In addition, ER positively depends on the belowground biomass [19]. However, there were different response trends of ER and BGB to changes in rainfall patterns. These might be due to the effective rainfall threshold of ER in middle growing seasons is greater than $2 \mathrm{~mm}[18,29]$.

\subsection{The Effect of Soil Moisture on Carbon Fluxes}

Rainfall alters NEE through changes in soil moisture [41]. In middle growing seasons, net ecosystem $\mathrm{CO}_{2}$ uptake was increased with increasing soil moisture (Figure 6). In addition, NEE switched towards a carbon sink when soil moisture was above the threshold of $8 \%$, because GPP was 
more enhanced than ER. Maximum net ecosystem $\mathrm{CO}_{2}$ uptake occurred with the 20-mm treatment, which can also be due to the highest soil water content (15\%-20\%).

In our study, soil moisture above $8 \%$ was necessary for maximum net ecosystem $\mathrm{CO}_{2}$ uptake in typical grasslands, while $6 \%$ was necessary for Africa savanna [42], $8 \%-14 \%$ for Tibetan alpine steppe [43], and $8 \%$ for shortgrass grasslands [29]. This also suggest that changes in rainfall patterns will play a more important role in carbon sequestration strength of Africa savanna.

We found a significant relationship between ER and soil moisture at surface depth $(0-10 \mathrm{~cm})$, which was explained by the root distribution. ER is the sum of soil respiration $\left(R_{S}\right)$ and plant autotrophic respiration $\left(R_{a}\right)$. Previous studies have shown that rhizosphere respiration dominates around $50 \%$ of the total $R_{s}$ during growing season in grasslands [44]. Moreover, $R_{a}$ contributes about $50 \%$ of the total ecosystem respiration in grasslands [45], especially in response to rainfall [13]. In our study, around $50 \%$ of root was distributed at a depth of $0-10 \mathrm{~cm}$, which resulted in the dominant role of $R_{s}$ and $R_{a}$ from soil surface depth. Therefore, soil moisture had significant effects on ER at surface depth in the growing season.

Soil temperature is also considered an important factor affecting carbon fluxes [46]. It is noteworthy that NEE was controlled by soil temperature in the early growing seasons than by soil moisture (Figure 5). This was because soil moisture content was more induced by lower evaporation resulting from lower soil temperature in the early growing seasons $\left(18^{\circ} \mathrm{C}\right.$ average in 5 years) than that in middle growing seasons $\left(22^{\circ} \mathrm{C}\right.$ average in 5 years). Therefore, the change in rainfall patterns may have a less influence on NEE in early growing seasons.

\subsection{Implications for Grassland C Cycling to Precipitation Patterns Change}

In conclusion, projected changes in the magnitude and frequency of precipitations necessitate identifying potential mechanisms of influence on carbon cycle in grasslands. Our study provides a fresh view in connection with changes in effects of rainfall patterns on the ecosystem carbon cycle. We found that net ecosystem $\mathrm{CO}_{2}$ uptake (-1*NEE) first increased, and then decreased, along with precipitation patterns, which was attributed to variations in soil moisture. In order to accurately evaluate the carbon cycle-precipitation relationship, we strongly suggest analyzing changes in rainfall treatments, especially for long-term events, taking into consideration ecological stress memory. We also found a discrepant relationship between rooting dynamics and soil moisture depth, highlighting that the response of root to precipitation may depend on rainfall patterns. Therefore, our conclusions on the effect of changes in rainfall patterns on plant root dynamics are helpful in understanding the response of plant communities to variations in rainfall regimes. Additionally, our results underscore the meaningful consideration of the relationship between NEE and soil temperature in the early growing season in current ecosystem models.

Supplementary Materials: The following are available online at http://www.mdpi.com/2071-1050/11/22/6376/s1, Figure S1: Daily precipitation (bars) and average soil moisture $(0-40 \mathrm{~cm}, \mathrm{SWC}$, lines) during the growing season in 2015, 2016 and 2017 over a semiarid grassland, Figure S2: Responses of aboveground biomass (AGB) to rainfall treatments. CK: ambient control, Figure S3: Responses of NEE (net ecosystem exchange), ER (ecosystem respiration), and GPP (gross primary production) to different rainfall treatments in middle growing season (from June to August) in 2015, 2016 and 2017, Figure S4: The relationship between normalized NEE (net ecosystem exchange), ER (ecosystem respiration), and GPP (gross primary production) and soil moisture at different depth $(0-10 \mathrm{~cm}$ and $10-20 \mathrm{~cm})$ in early growing season, Figure S5: The relationship between NEE (net ecosystem exchange), ER (ecosystem respiration), and GPP (gross primary production) and soil moisture at different depth $(0-10 \mathrm{~cm}$ and $10-20 \mathrm{~cm})$ in early growing season, Table S1: Results (i.e., $p$ values) of repeated measures ANOVAs on the effects of rainfall treatment (P), experimental year $(\mathrm{Y})$, and their interactions on biotic and abiotic variables, Table S2: Results from linear mixed effects model analysis of SoilM (soil moisture) and SoilT (soil temperature) at the depth of 0-10 cm and 10-20 cm effects on NEE (net ecosystem exchange), ER (ecosystem respiration), and GPP (gross primary production) in early growing season (May to June), Table S3: Results from linear mixed effects model analysis of SoilM (soil moisture) and SoilT (soil temperature) at the depth of 0-10 cm and 10-20 cm effects on NEE (net ecosystem exchange), ER (ecosystem respiration), and GPP (gross primary production) in middle growing season (May to June).

Author Contributions: Conceptualization, Z.H. and S.L.; methodology, Z.H., Q.G. and K.D.; data curation, K.D. and G.H.; writing—original draft preparation, Z.H. and G.H.; writing—review and editing, Z.H. and G.H.; funding acquisition, Z.H. 
Funding: This research was jointly supported by National Key R\&D Program of China (2016YFC0501603, 2017YFA060481), the National Natural Science Foundation of China (Grant NO. 31922053, 31570437), and the Startup Foundation for Talented Scholars in South China Normal University (S82360).

Conflicts of Interest: The authors declare no conflicts of interest.

\section{References}

1. Huxman, T.E.; Cable, J.M.; Ignace, D.D.; Eilts, J.A.; English, N.B.; Weltzin, J.; Williams, D.G. Response of net ecosystem gas exchange to a simulated precipitation pulse in a semi-arid grassland: The role of native versus non-native grasses and soil texture. Oecologia 2004, 141, 295-305. [CrossRef]

2. Huxman, T.E.; Snyder, K.A.; Tissue, D.; Leffler, A.J.; Ogle, K.; Pockman, W.T.; Sandquist, D.R.; Potts, D.L.; Schwinning, S. Precipitation pulses and carbon fluxes in semiarid and arid ecosystems. Oecologia 2004, 141, 254-268. [CrossRef]

3. IPCC Climate Change. The Physical Science Basis; Cambridge Univ. Press: Cambridge, UK, 2007.

4. Easterling, D.R.; Meehl, G.A.; Parmesan, C.; Changnon, S.A.; Karl, T.R.; Mearns, L.O. Climate extremes: Observations, modeling, and impacts. Science 2000, 289, 2068-2074. [CrossRef]

5. Trenberth, K.E.; Dai, A.; Rasmussen, R.M.; Parsons, D.B. The changing character of precipitation. Bull. Am. Meteorol. Soc. 2003, 84, 1205-1217. [CrossRef]

6. Tan, K.; Ciais, P.; Piao, S.; Wu, X.; Tang, Y.; Vuichard, N.; Liang, S.; Fang, J. Application of the ORCHIDEE global vegetation model to evaluate biomass and soil carbon stocks ofQinghai-Tibetan grasslands. Glob. Biogeochem. Cycles 2010, 24, GB1013. [CrossRef]

7. Flanagan, L.B.; Wever, L.A.; Carlson, P.J. Seasonal and inter-annual variation in carbon dioxide exchange and carbon balance in a northern temperate grassland. Glob. Chang. Biol 2012, 8, 599-615. [CrossRef]

8. Eswaran, H.; Van Den Berg, E.; Reich, P. DIVISION S-5 NOTES. Soil Sci. Soc. Am. J. 1993, 57, 192-194. [CrossRef]

9. Ahlstrom, A. The dominant role of semi-arid ecosystems in the trend and variability of the land CO2 sink. Science (80-) 2015, 120, 4503-4518. [CrossRef]

10. Guo, Q.; Li, S.; Hu, Z.; Zhao, W.; Yu, G.; Sun, X.; Li, L.; Liang, N.; Bai, W. Responses of gross primary productivity to different sizes of precipitation events in a temperate grassland ecosystem in Inner Mongolia, China. J. Arid Land 2016, 8, 36-46. [CrossRef]

11. Guo, Q.; Hu, Z.M.; Li, S.G.; Yu, G.R.; Sun, X.M.; Li, L.H.; Liang, N.S.; Bai, W.M. Exogenous N addition enhances the responses of gross primary productivity to individual precipitation events in a temperate grassland. Sci. Rep. 2016, 6, 1-9. [CrossRef]

12. Hu, Z.; Guo, Q.; Li, S.; Piao, S.; Knapp, A.K.; Ciais, P.; Li, X.; Yu, G. Shifts in the dynamics of productivity signal ecosystem state transitions at the biome-scale. Ecol. Lett. 2018. [CrossRef] [PubMed]

13. Chen, S. dependence of carbon sequestration on the differential response of ecosystem photosynthesis and respiration to rain pulses in a semiarid steppe. GCB 2009, 110, 115-126. [CrossRef]

14. Thomey, M.L.; Collins, S.L.; Vargas, R.; Johnson, J.E.; Brown, R.F.; Natvig, D.O.; Friggens, M.T. Effect of precipitation variability on net primary production and soil respiration in a Chihuahuan Desert grassland. Glob. Chang. Biol. 2011, 17, 1505-1515. [CrossRef]

15. Gao, Y.Z.; Chen, Q.; Lin, S.; Giese, M.; Brueck, H. Resource manipulation effects on net primary production, biomass allocation and rain-use efficiency of two semiarid grassland sites in Inner Mongolia, China. Oecologia 2011, 165, 855-864. [CrossRef] [PubMed]

16. Hao, Y.B.; Zhou, C.T.; Liu, W.J.; Li, L.F.; Kang, X.M.; Jiang, L.L.; Cui, X.Y.; Wang, Y.F.; Zhou, X.Q.; Xu, C.Y. Aboveground net primary productivity and carbon balance remain stable under extreme precipitation events in a semiarid steppe ecosystem. Agric. For. Meteorol. 2017, 240-241, 1-9. [CrossRef]

17. Li, L.; Zheng, Z.; Biederman, J.A.; Xu, C.; Xu, Z.; Che, R.; Wang, Y.; Cui, X.; Hao, Y. Ecological responses to heavy rainfall depend on seasonal timing and multi-year recurrence. New Phytol. 2019. [CrossRef]

18. Hao, Y.; Wang, Y.; Mei, X.; Cui, X. The response of ecosystem CO2 exchange to small precipitation pulses over a temperate steppe. Plant Ecol. 2010, 209, 335-347. [CrossRef]

19. Bai, W.; Wan, S.; Niu, S.; Liu, W.; Chen, Q.; Wang, Q.; Zhang, W.; Han, X.; Li, L. Increased temperature and precipitation interact to affect root production, mortality, and turnover in a temperate steppe: Implications for ecosystem C cycling. Glob. Chang. Biol. 2010, 16, 1306-1316. [CrossRef] 
20. Fan, Y.; Miguez-Macho, G.; Jobbágy, E.G.; Jackson, R.B.; Otero-Casal, C. Hydrologic regulation of plant rooting depth. Proc. Natl. Acad. Sci. USA 2017, 114, 10572-10577. [CrossRef]

21. Potts, D.L.; Huxman, T.E.; Enquist, B.J.; Weltzin, J.F.; Williams, D.G. Resilience and resistance of ecosystem functional response to a precipitation pulse in a semi-arid grassland. J. Ecol. 2006, 94, 23-30. [CrossRef]

22. Bae, K.; Koo, D.; Timothy, L.; Lee, Y. Seasonal variation of soil respiration rates in a secondary forest and agroforestry systems. Agrofor. Syst. 2013, 87, 131-139. [CrossRef]

23. Liu, L.; Greaver, T.L. A review of nitrogen enrichment effects on three biogenic GHGs: The CO 2 sink may be largely offset by stimulated N2O and CH 4 emission. Ecol. Lett. 2009, 12, 1103-1117. [CrossRef]

24. Niu, S.; Luo, Y.; Fei, S.; Montagnani, L.; Bohrer, G.; Janssens, I.A.; Gielen, B.; Rambal, S.; Moors, E.; Matteucci, G. Seasonal hysteresis of net ecosystem exchange in response to temperature change: Patterns and causes. Glob. Chang. Biol. 2011, 17, 3102-3114. [CrossRef]

25. Hu, Z.; Yu, G.; Fu, Y.; Sun, X.; Li, Y.; Shi, P.; Wang, Y.; Zheng, Z. Effects of vegetation control on ecosystem water use efficiency within and among four grassland ecosystems in China. Glob. Chang. Biol. 2008, 14, 1609-1619. [CrossRef]

26. Jia, X.; Zha, T.; Gong, J.; Zhang, Y.; Wu, B.; Qin, S.; Peltola, H. Multi-scale dynamics and environmental controls on net ecosystem CO2exchange over a temperate semiarid shrubland. Agric. For. Meteorol. 2018, 259, 250-259. [CrossRef]

27. Yuan, W.; Piao, S.; Qin, D.; Dong, W.; Xia, J.; Lin, H.; Chen, M. Influence of Vegetation Growth on the Enhanced Seasonality of Atmospheric CO2. Glob. Biogeochem. Cycles 2018, 32, 32-41. [CrossRef]

28. Davidson, E.A.; Samanta, S.; Caramori, S.S.; Savage, K. The Dual Arrhenius and Michaelis-Menten kinetics model for decomposition of soil organic matter at hourly to seasonal time scales. Glob. Chang. Biol. 2012, 18, 371-384. [CrossRef]

29. Parton, W.; Morgan, J.; Smith, D.; Del Grosso, S.; Prihodko, L.; Lecain, D.; Kelly, R.; Lutz, S. Impact of precipitation dynamics on net ecosystem productivity. Glob. Chang. Biol. 2012, 18, 915-927. [CrossRef]

30. Yuhui, W.; Jiquan, C.; Guangsheng, Z.; Changliang, S.; Jun, C.; Yu, W.; Jianmin, S. Predominance of precipitation event controls ecosystem CO2exchange in an Inner Mongolian desert grassland, China. J. Clean. Prod. 2018, 197, 781-793. [CrossRef]

31. Oliver, T.H.; Heard, M.S.; Isaac, N.J.B.; Roy, D.B.; Procter, D.; Eigenbrod, F.; Freckleton, R.; Hector, A.; Orme, C.D.L.; Petchey, O.L.; et al. A Synthesis is Emerging between Biodiversity-Ecosystem Function and Ecological Resilience Research: Reply to Mori. Trends Ecol. Evol. 2016, 31, 89-92. [CrossRef]

32. Walter, J.; Nagy, L.; Hein, R.; Rascher, U.; Beierkuhnlein, C.; Willner, E.; Jentsch, A. Do plants remember drought? Hints towards a drought-memory in grasses. Environ. Exp. Bot. 2011, 71, 34-40. [CrossRef]

33. Knapp, A.K.; Beier, C.; Briske, D.D.; Classen, A.T.; Luo, Y.; Reichstein, M.; Smith, M.D.; Smith, S.D.; Bell, J.E.; Fay, P.A.; et al. Consequences of More Extreme Precipitation Regimes for Terrestrial Ecosystems. Bioscience 2008, 58, 811-821. [CrossRef]

34. Rastetter, E.B.; King, A.W.; Cosby, B.J.; Hornberger, G.M.; Neill, R.V.O.; Hobbie, J.E. Aggregating Fine-Scale Ecological Knowledge to Model Coarser-Scale Attributes of Ecosystems Published by: Ecological Society of America Stable URL: http://www.jstor.org/stable/1941889 Your use of the JSTOR archive indicates your acceptance of JSTOR' s. America (N. Y.) 1992, 2, 55-70.

35. Harpole, W.S.; Potts, D.L.; Suding, K.N. Ecosystem responses to water and nitrogen amendment in a California grassland. Glob. Chang. Biol. 2007, 13, 2341-2348. [CrossRef]

36. Reich, P.B.; Hobbie, S.E.; Lee, T.D. Plant growth enhancement by elevated CO2 eliminated by joint water and nitrogen limitation. Nat. Geosci. 2014, 7, 920-924. [CrossRef]

37. Niu, S.; Wu, M.; Han, Y.; Xia, J.; Zhang, Z.; Yang, H.; Wan, S. Nitrogen effects on net ecosystem carbon exchange in a temperate steppe. Glob. Chang. Biol. 2010, 16, 144-155. [CrossRef]

38. $\mathrm{Xu}, \mathrm{W}$.; Yuan, W. Responses of microbial biomass carbon and nitrogen to experimental warming: A meta-analysis. Soil Biol. Biochem. 2017, 115, 265-274. [CrossRef]

39. Isbell, F.; Craven, D.; Connolly, J.; Loreau, M.; Schmid, B.; Beierkuhnlein, C.; Bezemer, T.M.; Bonin, C.; Bruelheide, H.; De Luca, E.; et al. Biodiversity increases the resistance of ecosystem productivity to climate extremes. Nature 2015, 526, 574-577. [CrossRef]

40. Bai, Y.; Xingguo, H.; Jianguo, W.; Zuozhong, C.; Linghao, L. Ecosystem stability and compensatory effects in the Inner Mongolia grassland. Nature 2004, 43, 181-184. [CrossRef] 
41. Green, J.K.; Seneviratne, S.I.; Berg, A.M.; Findell, K.L.; Lawrence, D.M.; Gentine, P. Large influence of soil moisture variability on long-term terrestrial carbon uptake. Nature 2019. accepted. [CrossRef]

42. Williams, C.A.; Hanan, N.; Scholes, R.J.; Kutsch, W. Complexity in water and carbon dioxide fluxes following rain pulses in an African savanna. Oecologia 2009, 161, 469-480. [CrossRef]

43. Zhou, X.; Wan, S.; Luo, Y. Source components and interannual variability of soil CO2 efflux under experimental warming and clipping in a grassland ecosystem. Glob. Chang. Biol. 2007, 13, 761-775.

44. Wan, S.; Luo, Y. Substrate regulation of soil respiration in a tallgrass prairie: Results of a clipping and shading experiment. Glob. Biogeochem. Cycles 2003, 17, 1-12. [CrossRef]

45. Hanson, P.J.; Edwards, N.T.; Garrten, C.T.; Andrews, J.A. Separating Root and Soil Microbial Contributions to Soil Respiration: A Review of Methods and Observations. Biogeochemistry 2000, 48, 115-146. [CrossRef]

46. Reich, P.B.; Hungate, B.A.; Luo, Y. Carbon-Nitrogen Interactions in Terrestrial Ecosystems in Response to Rising Atmospheric Carbon Dioxide. Ann. Rev. Ecol. Evol. Syst. 2006, 37, 611-636. [CrossRef]

(C) 2019 by the authors. Licensee MDPI, Basel, Switzerland. This article is an open access article distributed under the terms and conditions of the Creative Commons Attribution (CC BY) license (http://creativecommons.org/licenses/by/4.0/). 